\title{
IoT-Based Framework for Smart Waste Monitoring and Control System, A Case Study of the Smart Cities ${ }^{\dagger}$
}

\author{
Sani Abba * and Chinaka Ihechukwu Light \\ Department of Mathematical Sciences (Computer Science), Faculty of Science, Abubakar Tafawa Balewa \\ University (Federal University of Technology), Yelwa campus, Dass road, P.M.B. 0248 Bauchi state, Nigeria; \\ chinakalight@googlemail.com. \\ * Correspondence: saniabba2004@ieee.org; Tel.: +234-0811-9717-843 \\ + Presented at the 7th Electronic Conference on Sensors and Applications, 15-30 November 2020; Available \\ online: https://ecsa-7.sciforum.net/.
}

Published: 15 November 2020

\begin{abstract}
The environmental sanitation is very essential for healthy living. In our daily livelihood, garbage bins are usually kept without proper monitoring until they are being filled and overflow on the surrounding, and spills out, resulting in environmental pollution, which has a serious health related issues to human beings and the environment. For smart cities, the garbage bins need to be monitored and controlled to ensure a healthy and clean environment. In the present technological advancement, real-time monitoring and control of waste disposal is a challenging area which needs an urgent attention by the research community. The traditional approach of monitoring waste in garbage bins placed in strategic locations is a very tedious and inefficient way that consumes time, human effort, cost, and this is not in agreement with smart city requirements. This research paper presents the design and implementation of an IoT-based Arduino microcontroller working with the ultrasonic sensors that detects the level of waste in the garbage bin placed from garbage locations and constantly at regular intervals display the status information as FILLED, HALF-FILLED or EMPTY on an LCD screen, as well as send the content level information at those intervals to a central web-server system that displays the garbage bin levels graphically. This is achieved using a microcontroller, Wi-Fi module and ultrasonic sensors. The programming of the Arduino uno microcontroller was done with an Arduino IDE and embedded C programming language. The communication with the web-server was done using the hypertext pre-processor (PHP) scripting programming language. The prototype was designed and simulated using Proteus 8.0 professional simulation software. This process helps to automate garbage bin monitoring and control. Experimental results demonstrate a promising solution to waste management and control. A number of testing had been performed to evaluate the device workability in real situations. The measured distances from the garbage bins are transmitted to the website. This webpage performs analytic and visualization and displays a bar-chart showing the levels of the garbage waste, time, and location in real-time for viewing. The proposed prototype is an innovative system which will help to keep the smart cities clean and tidy using ultrasonic sensors.
\end{abstract}

Keywords: ultrasonic sensors; smart waste monitoring and control; Internet of Things (IoT); smart cities; waste bins

\section{Introduction}

At the present time, our environment is being polluted by massive deposits of global waste. This will have a catastrophic effect on human life and the surrounding. It was anticipated that the global waste will grow by $70 \%$ by the year 2050 unless immediate necessary measures of monitoring and control are put in place according to the world bank report [1]. In addition, due to high increase in 
global population and urbanization, the volume of waste produced globally is expected to rise to 3.4 billion tones within the next three decades. The use of modern and innovative technologies will pave way for the betterment and monitoring and control of waste as compared with the traditional approach which make use of human labor, garbage bins, and disposal trucks.

Garbage is an unwanted material such as rubbish or waste that is disposed from homes, cities, public centers, schools, markets, industries, etc. It is regarded as waste material that is discarded by humans, mainly due to lack of utility. The rapid increase and buildup of waste in our society has a serious concern, especially when monitoring and control measures are not properly maintained [2].

In smart cities were environmental pollution is supposed to be graciously reduced, sanitation measures are vital and cleanliness begins with providing garbage bins for waste disposal at strategic locations. Real-time monitoring and control of garbage bins placed in strategic locations and disposal at the final destination is very essential [3].

The high increase in industrialization and human population resulted in higher levels of garbage generated in urban areas. Therefore, the number of garbage bins needs to be increased and placed in strategic locations for real-time monitoring and collection to save the environment. Without the proper collection and disposal of the waste, the garage bins would be filled or overfilled and spills out of the surrounding and causes health related problems to human beings and the environment [4].

As the volume of solid waste increases rapidly, waste management is becoming a big challenge to authorities and governments handling them, therefore, it becomes imperative to tackle the problem using modern technologies to provide the needed solution [5]. This research paper presents an innovative system which will help to keep the cities clean by implementing a system that would help to monitor and control, and provide real-time communication between the garbage bins and the garbage collection personnel (truck driver) via an organized web-based system depending on the status of the garbage bins. This approach, will helps to keep the smart city clean and hygienic for better living.

This research paper aimed to overcome the shortcomings of the previously reported works. The previous approaches didn't allow real-time monitoring and control of the garbage bins levels and didn't have a central monitoring and control system where the data or information regarding the garbage bin will be sent to for proper decision making by the concerned authorities responsible for waste control and management. Furthermore, this research paper aimed to provide a better solution to the stated problem by creating a central system that collect these data and then smartly display the graphical information of levels of the garbage bins so that the authorities can make real-time and cost-effective decision that would be beneficial to all and ultimately keep the environment clean.

This research paper is an innovative system which will help to keep the smart cities clean and tidy. The proposed system monitors the garbage bins and informs about the level of garbage collected in the garbage bins via a web page. The system makes use of ultrasonic sensors placed over the bins to detect the garbage level and compare it with the garbage bin's depth. A web page was built to display the status information to the end users. The web page gives a graphical view of the garbage bins and highlights the garbage collected in color in order to show the level of garbage collected. In addition, a Liquid crystal display (LCD) screen displays the status of the garbage level. Thus, this innovative system helps to keep the city clean by informing the end users and authorities concerned about the garbage levels of the bins by providing a graphical image of the bins via a web page.

This study will be of immense importance not just to those whose jobs are majorly disposal of refuse bins, but to the entire public adopting the smart cities guidelines for better living. The implementation of this proposed approach, will go a long way in making efficient use of waste disposal in real-time as well as the optimal use of resources and go a long way to improve the living condition of the smart city dwellers. Finally, the design and implementation of the working prototype system, will serve as an innovative and informative way of keeping and improving the health condition of the smart city dwellers. The salient contributions of this research paper are as follows:

1. A working prototype for the identification of garbage bins to know its location and increase efficiency to empty it in real-time.

2. Autonomous monitoring and control of the garbage bins level using an ultrasonic sensor. 
3. The garbage bins, send data to a web application via a Wi-Fi modem.

4. An LCD screen and light emitting diodes (LEDs) are used to display the status of the garbage bins to the end user.

5. A web-saver and web page interfaces were designed to graphically display the level of the garbage bins.

\section{Related Works}

Nowadays, the smart cities are highly populated due to rural migrant inflow to the urban cities. This causes a significant increase in waste disposal and causes harmful effects to human being and the environment. Due to the lack of proper monitoring and control of waste, the garbage bins mainly appear to be flooded and spills out on the surrounding causing many health-related issues. This situation should be taken into serious consideration by the relevant authorities and the research community to provide a solution in order to manage, monitor, and control the waste disposal. The use of IoT-Based solution will help in providing a lasting solution to waste monitoring and control [6].

The authors Padini et al. [7], presented a hardware and software approach to waste management that allows the users to be part of the management process. The proposed system employs the use of IoT technology that constantly monitor the level of waste in garbage bins in real-time. The sensed data are stored and processed using a middleware and providing a statistical information regarding the status of the waste in the garbage bins. Users can obtain the waste information through a webpage or mobile application. A prototype was presented and a use case evaluation of the approach was demonstrated and validated.

The authors You et al. [8], proposed an informatization scheme that combines multiple technologies to monitor illegal behavior in waste disposal in real-time. The scheme provides a means of evaluating the performance of stakeholders involved in the process and strengthening the collaboration among supervisory departments. The authors presented a case study to demonstrate the feasibility and effectiveness of their approach. Results from their system testing, indicated that the total sum of illegal cases has significantly reduced from 510 to 89 per annum since the adoption of the new system.

The authors Jaid Jim et al. [9], presented a garbage management system that combines the basic ideas of waste management and the internet of things technology namely, internet of garbage bins (IoGB). The proposal makes use of smart cycle containers that cycles individually after being filled with garbage waste. This approach helps to solve the problem of lack of space of putting the garbage bins in a strategic way. A server-based monitoring system was used to control an autonomous car that collects the waste when needed.

Shi et al. [10], proposed a solution to waste disposal and collection problems in urban areas. The approach modeled a multi depot vehicle routing problem as a means of collecting waste from the collection centers to reduce the means of transportation. A heuristic technique was adopted to provide a solution to the problem.

Hussain et al. [11], presented an IoT-based smart bin employing a machine and deep learning model to tackle the problem of waste disposal and to provide an information based on the forecast of air pollution associated with the garbage bin in the environment. An IoT-based server is interfaced with the garbage bin. The google cloud server provides the computation needed to report the status of the bin and to provide the real-time forecasting information on the status of air quality surrounding the garbage bins in real-time. The benefits of the proposed approach in terms of improved accuracy, using machine learning were demonstrated.

Laurieri et al. [12], presented a survey based on citizen's habit in generating and managing recycle waste and the financial cost and environmental impacts of the adopted door-to-door waste collection scheme in Altamura, Italy. The authors proposed a weekly garbage bin collection scheme to provide an efficient and waste collection services to the people living in the town. This approach is an aim to design a smart device to assist people in proper handling of waste management. 
Moreschi et al. [13], presented a study based on a case study of a city in Italy namely, Genoa. This is as a result of the closure of the Scarpino landfill that was preserved for the disposal of garbage waste in the municipal city. The study provided a multi-objective tool that can be used for long-term planning and scheduling of daily activities. A decision support system for waste management was presented. The effectiveness in long-term targets in relation to the total cost, the amount of emissions produced by the garbage waste transportation and the utilization of an individual plant for sustainable development was demonstrated. Finally, other interesting approaches that employed the use of IoT-based technologies for monitoring and control applications are provided in our previous works [14-18].

\section{System Architecture}

Figure 1a illustrates the block diagram of the architecture of the proposed system. The IoT based smart waste monitoring and control system consists of seven units. This prototype device, consists of the waste bin unit; ultrasonic sensor unit; power supply unit; monitoring and control unit; liquid crystal display (LCD) unit; light emitting diode (LED) unit; Wi-Fi connectivity unit; and user interface unit. The overall system operation is controlled by a single microcontroller (monitoring and control unit). This unit is programmed based on how other peripherals and components of the system will behave. The Ultrasonic sensors are used to detect the garbage distance inside the garbage bin. The ultrasonic sensor poses the capabilities to measure the distance to or from an object by using sound waves. The sensor determines and measure the distance by transmitting a sound wave at a particular frequency and listening to the sound wave to bounce back. In order to determine the distance between the sonar and the object, the time difference between when the sound wave is transmitted and when the wave is bounced back is computed. However, it's essential to know that some objects may not be detected by the ultrasonic sensors [19]. The sensed data from the sensors are monitored and controlled in the monitoring and control unit. The light emitting diode unit provides status information on the levels of garbage in the garbage bins. If the level is less than $50 \%$, the GREEN LED will TURN ON and the status message will be EMPTIED, and the measured distance will be displayed. If the level is greater than $50 \%$ and less than $70 \%$, the YELLOW LED will TURN ON and the status message will be HALL-FILLED, and the measured distance will be displayed. If the level is above 70\% the RED LED will TURN ON and the status message will be FILLED, and the measured distance will be displayed. The processed data will be displayed on the LCD screen and also sent to the remote server via the Wi-Fi module which would store the information in a database. A web application was designed and implemented using PHP programming language to query the data from the database through a Wi-Fi connectivity and display the information on a webpage for remote viewing and monitoring. Users can access the garbage status or level information through the website. The website can be accessed with the use of electronic gadgets such as laptop, desktop and smartphone devices. The sensed data will be uploaded to data log file and updated continuously. The displayed data on the webpage will be updated in every $5 \mathrm{~min}$. Figure $1 \mathrm{~b}$ illustrates the proposed system flowchart. 


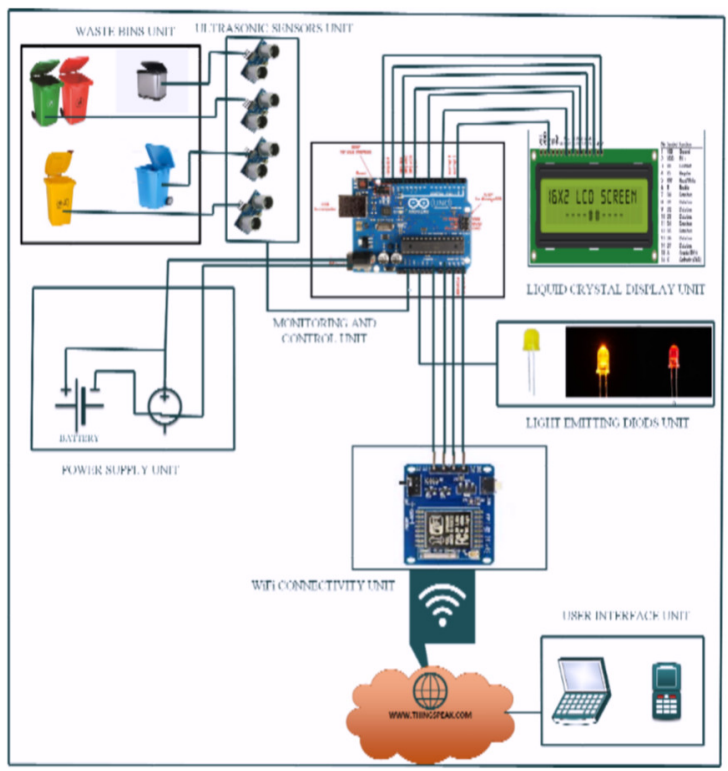

(a)

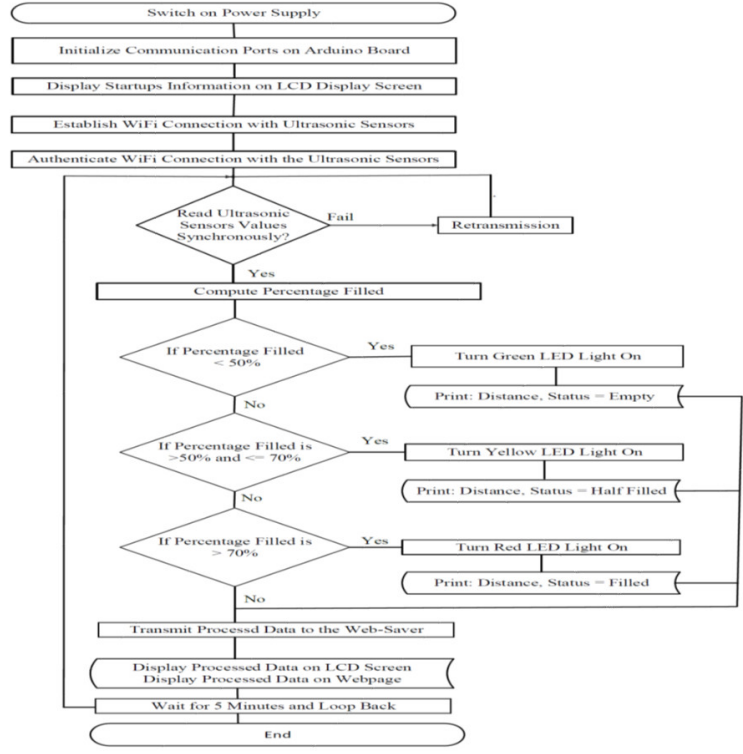

(b)

Figure 1. (a) System architecture block diagram (b) Proposed system flowchart.

\subsection{System Simulation and Design}

Figure 2 illustrates the schematic diagram of the simulated system using Proteus professional 8.0 design environment [20]. The major goal of this research paper is the creation of the firmware program in embedded $C$ programming language that monitor and control the sensors and other peripheral devices. This is because the microcontroller controls all the processes in the entire system. The programming of the Arduino uno was done with Arduino IDE [21].

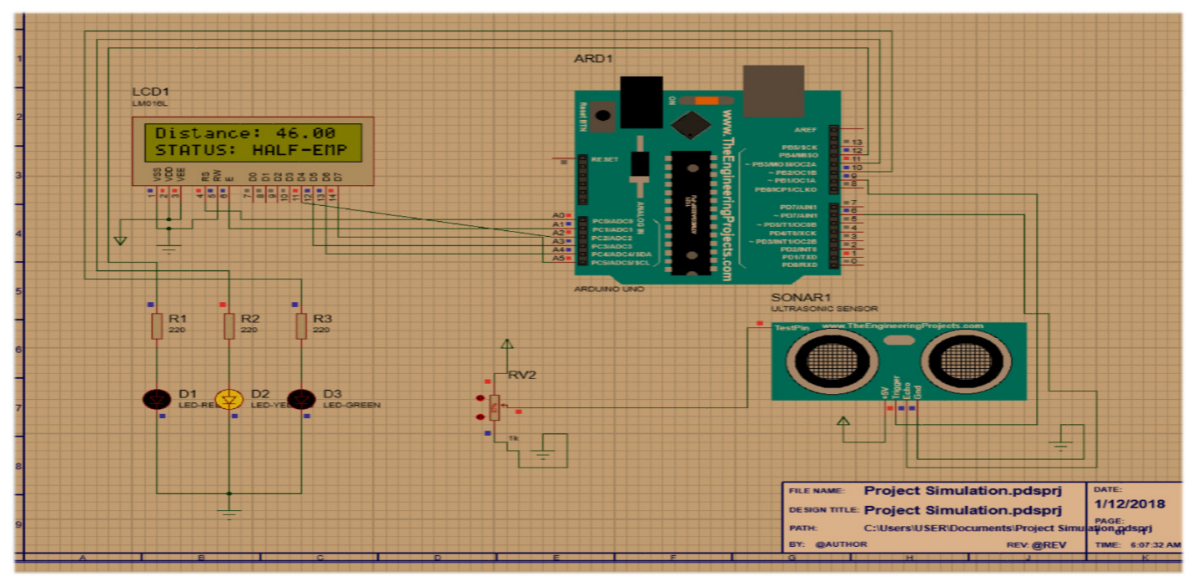

Figure 2. Simulation schematic block diagram.

\section{Experimental Results}

Several experiments were conducted using the designed device prototype. The results are obtained from the outputs gotten from the sensor reading stored in the website (http://www.garbageiot.herokuapp). Several numbers of testing had been performed to evaluate the device workability in real situations. The measured distance from the garbage bin is transmitted to the website. This webpage performs analysis, visualization, and displays a bar-chart showing the levels of the garbage waste, time, and location in real-time for viewing. It is essential to monitor and control the garbage height and distance parameters in order to track the level of the garbage in the bins. This would ensure that the values displayed by the central server system are accurate and reliable to be used by the smart city dwellers. 
Figure 3a-c illustrate the garbage waste level indicators. The RED LED light on the LED light unit will illuminate to indicate that the garbage bin is almost FILLED. And this will be displayed in the RED bar-chart graph as shown in Figure 3a. When the status of the garbage bin is HALF-FILLED, the YELLOW LED light will illuminate and the result will be displayed using a YELLOW bar-chart as illustrated in Figure 3b. The status of the garbage bin is almost EMPTY, this happens when the GREEN LED light illuminates and the GREEN bar-chart is displayed as illustrated in Figure 3c.

In a highly populated city, this will help to keep the cities clean and tidy. In addition, this will ensure enormous advances in technology most especially in this present age where there is a tremendous advancement in creativity and in using technology to better the lives of the smart city dwellers and the environment.

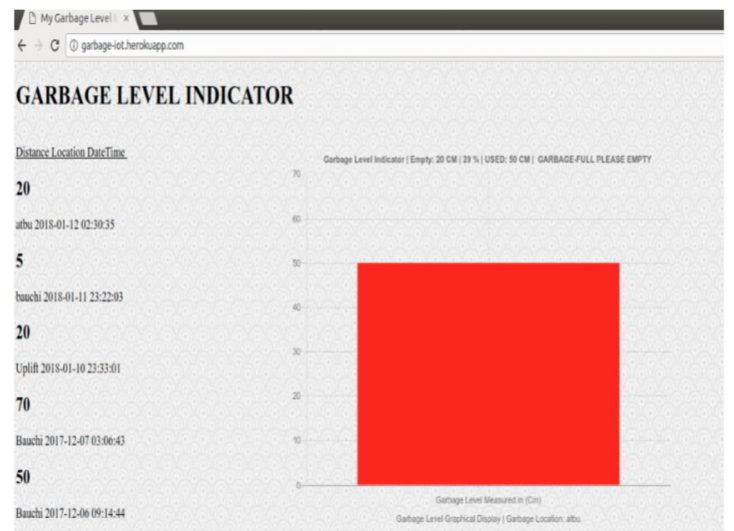

(a)

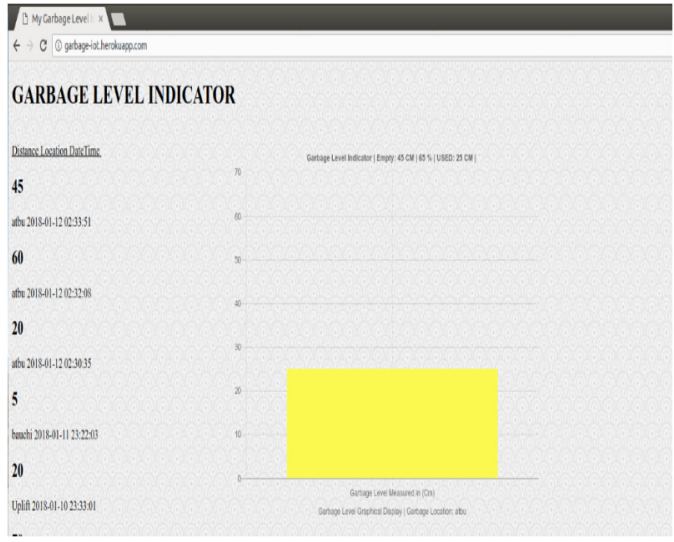

(b)

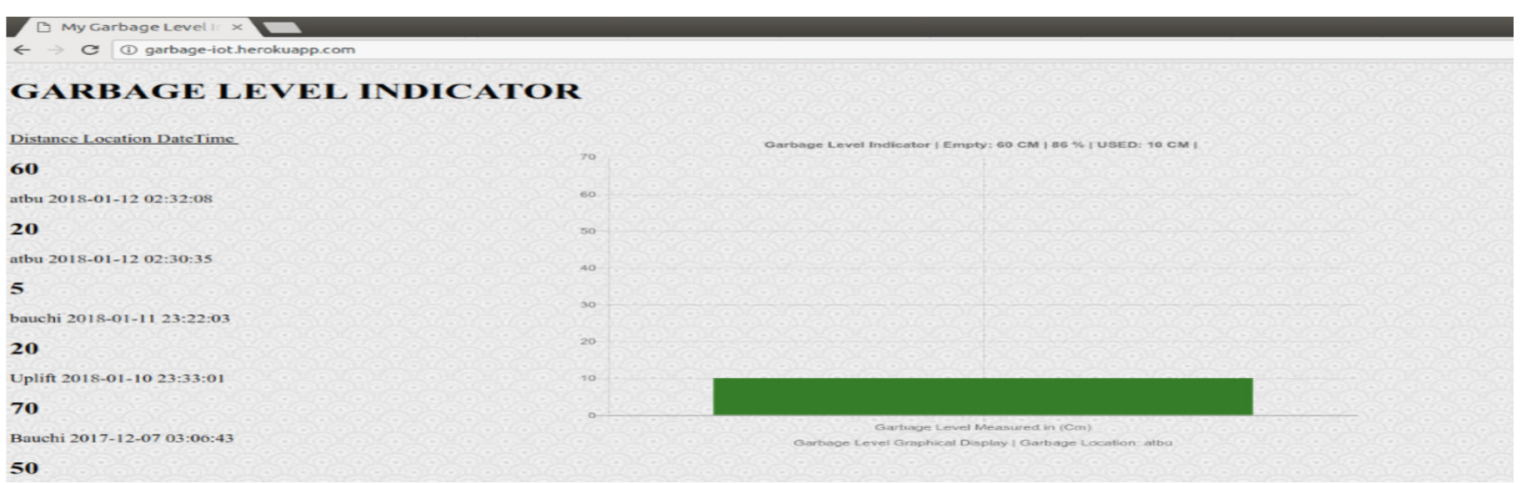

(c)

Figure 3. (a) The garbage status is almost FILLED, is due for collection (b) The garbage status is HALFFILLED (c) The garbage status is almost EMPTY.

\section{Conclusions}

This research paper presents an innovative approach to facilitate the process of keeping the environment clean, tidy, and conducive for living. The proposed approach, presented the design and implementation methodology to strategically monitor and control the rate at which garbage bins are filled and eventually help prevent overflow which in most cases leads to environmental pollution. The research paper presents the design and implementation of an IoT-based Arduino microcontroller working with the ultrasonic sensors that detects the level of waste in the garbage bin placed from garbage locations and constantly at regular intervals display the status information as FILLED, HALF-FILLED or EMPTY on an LCD screen, as well as send the content level information at those intervals to a central web-server system that displays the garbage bin levels graphically. This is achieved using a microcontroller, Wi-Fi module and ultrasonic sensors. The programming of the Arduino uno microcontroller was done with an Arduino IDE and embedded C programming language. The communication with the web-server was done using the hypertext pre-processor 
(PHP) scripting programming language. The prototype was designed and simulated using Proteus 8.0 professional simulation software. This process helps to automate garbage bin monitoring and control. Experimental results demonstrate a promising solution to waste management and control. Future work will consider the use of the field programmable gate array (FPGA) to provide high performance real-time computing capabilities compared with the Arduino microcontroller. The proposed system can be extended to monitor and control waste in remote locations for sustainable development.

Author Contributions: Conceptualization, S.A.; Data curation, C.I.L.; Formal analysis, S.A., C.I.L.; Funding acquisition, S.A.; Investigation, S.A. and C.I.L.; Methodology, S.A. and C.I.L.; Project administration, S.A.; Resources, C.I.L.; Software, S.A. and C.I.L.; Supervision, S.A.; Validation, S.A., C.I.L ; Visualization, S.A., and C.I.L.; Writing-original draft, S.A.; Writing-review \& editing, S.A. All authors have read and agreed to the published version of the manuscript.

Acknowledgments: Special thanks are owed to Maria, Liz Crespo of the Abdussalam International Centre for Theoretical Physics (ICTP), Trieste, Italy and Iain Darby of the International Atomic Energy Agency (IAEA), Vienna, Austria, for the ICTP workshop/seminar, smr: 3143, “Joint ICTP-IAEA School on Zynq-7000 SoC and its Applications for Nuclear and Related Instrumentation", 21 Aug.-15 Sep., 2017, Trieste, Italy.

Conflicts of Interest: The authors declare no conflict of interest.

\section{References}

1. World Bank Report, Washington September 20, 2018. Available online: https://www.worldbank.org/en/news/press-release/2018/09/20/global-waste-to-grow-by-70-percent-by2050-unless-urgent-action-is-taken-world-bank-report, (accessed on 12 August 2020).

2. Wikipedia Online Encyclopedia. Available online: https://en.wikipedia.org/wiki/Garbage (accessed on 12 August 2020).

3. Giffinger, R. Smart cities Ranking of European medium sized cities. Cent. Reg. Sci. Vienna Univ. Technol. 2017, 16, 13-18.

4. Akhil, R.N.; Valarmathie, P.N. IoT Based Waste Management System for Smart Cities. Int. J. Adv. Res. Ideas Innov. Technol. 2007, 3.

2. Sonal, C.; Priya, K.; Shruti, S.; Prajakta, P.; Snehal, S.; Shweta, M. Real Time Smart City Garbage Collection and Monitoring System Using GSM and GPS. Int. Res. J. Eng. Technol. 2017, 4, 126-129.

3. Ruhin, M.S.; Drishya, G.; Harish, K.S.; Mohammed, S.N.; Lakshmi, S. A Survey on Smart Garbage Management in Cities using IoT. Int. J. Eng. Comput. Sci. 2016, 5, 18749-18754, ISSN: 2319-7242.

4. Pardini, K.; Rodrigues, J.J.; Diallo, O.; Das, A.K.; de Albuquerque, V.H.C.; Kozlov, S.A. A Smart Waste Management Solution Geared towards Citizens. Sensors 2020, 20, 2380.

5. You, Z.; Wu, C.; Zheng, L.; Feng, L. An Informatization Scheme for Construction and Demolition Waste Supervision and Management in China. Sustainability 2020, 12, 1672.

6. Jaid Jim, A.A.; Kadir, R.; Mamun, M.A.A.; Nahid, A.-A.; Ali, M.Y. A Noble Proposal for Internet of Garbage Bins (IoGB). Smart Cities 2019, 2, 214-229.

7. Shi, Y.; Lv, L.; Hu, F.; Han, Q. A Heuristic Solution Method for Multi-Depot Vehicle Routing-Based Waste Collection Problems. Appl. Sci. 2020, 10, 2403.

8. Hussain, A.; Draz, U.; Ali, T.; Tariq, S.; Irfan, M.; Glowacz, A.; Antonino Daviu, J.A.; Yasin, S.; Rahman, S. Waste Management and Prediction of Air Pollutants Using IoT and Machine Learning Approach. Energies 2020, 13, 3930.

9. Laurieri, N.; Lucchese, A.; Marino, A.; Digiesi, S. A Door-to-Door Waste Collection System Case Study: A Survey on its Sustainability and Effectiveness. Sustainability 2020, 12, 5520.

10. Moreschi, L.; Del Borghi, A.; Taramasso, A.C.; Gallo, M. Waste Management under Emergency Conditions: Life-Cycle Multicriteria Analysis as Decision Support System. Resources 2020, 9, 82.

11. Abba, S.; Wadumi, N.J.; Lee, J.A.; Liz Crespo, M. Design and Performance Evaluation of a Low-Cost Autonomous Sensor Interface for a Smart IoT-Based Irrigation Monitoring and Control System. Sensors 2019, 19, 3643.

12. Abba, S.; Garba, A.M. An IoT-Based Smart Framework for a Human Heartbeat Rate Monitoring and Control System. Proceedings 2020, 42, 36. 
13. Abba, S.; Lee, J.A. FPGA-Based Design of an Intelligent On-Chip Sensor Network Monitoring and Control Using Dynamically Reconfigurable Autonomous Sensor Agents. Int. J. Distrib. Sens. Netw. 2016, 29, 4246596.

14. Sani, A.; Itse, M.N. Design and Evaluation of a Low-Cost and Flexible Data Acquisition System Using Sensor Network for Smart Homes. Sens. Transducers 2018, 227, 73-81.

15. Sani, A.; Beauty, P.E. Smart Framework for Environmental Pollution Monitoring and Control System Using IoT-Based Technology. Sens. Transducers 2019, 229, 84-93.

16. Ashima, B.; Sumanth, R. Garbage Monitoring System Using IOT. Int. J. Pure Appl. Math. 2017, 114, $155-161$. Available online: http://acadpubl.eu/jsi/2017-114-7-ICPCIT-2017/articles/12/18.pdf (accessed on).

17. Lab-center Electronics Ltd. Proteus Design Suite 8.5 Professional. Available online: http://www.labcenter.com (accessed on 10 June 2020).

18. Arduino Integrated Design Environment. Available online: http://www.arduino.cc (accessed on 8 June 2020).

Publisher's Note: MDPI stays neutral with regard to jurisdictional claims in published maps and institutional affiliations.

(C) 2020 by the authors. Submitted for possible open access publication under the terms and conditions of the Creative Commons Attribution (CC BY) license (http://creativecommons.org/licenses/by/4.0/). 